\title{
Intravenous palonosetron increases the incidence of QTc prolongation during sevoflurane general anesthesia for laparotomy
}

\author{
Jeong Jin Min, Yongjae Yoo, Tae Kyong Kim, and Jung-Man Lee \\ Department of Anesthesiology and Pain Medicine, Seoul National University Hospital, Seoul National University College of \\ Medicine, Seoul, Korea
}

Background: Palonosetron is a recently introduced 5-hydroxytryptamine-3 $\left(5-\mathrm{HT}_{3}\right)$ receptor antagonist useful for postoperative nausea and vomiting prophylaxis. However, $5-\mathrm{HT}_{3}$ receptor antagonists increase the corrected QT (QTc) interval in patients who undergo general anesthesia. This retrospective study was performed to evaluate whether palonosetron would induce a QTc prolongation in patients undergoing general anesthesia with sevoflurane.

Methods: We reviewed a database of 81 patients who underwent general anesthesia with sevoflurane. We divided the records into palonosetron $(n=41)$ and control $(n=40)$ groups according to the use of intraoperative palonosetron, and analyzed the electrocardiographic data before anesthesia and 30, 60, 90, and $120 \mathrm{~min}$ after skin incision. Changes in the QTc interval from baseline, mean blood pressure, heart rate, body temperature, and sevoflurane concentrations at each time point were compared between the two groups.

Results: The QTc intervals at skin incision, and 30, 60, 90, and 120 min after the skin incision during general anesthesia were significantly longer than those at baseline in the two groups $(\mathrm{P}<0.001)$. The changes in the QTc intervals were not different between the two groups $(\mathrm{P}=0.41)$. However, six patients in the palonosetron group showed a QTc interval $>500 \mathrm{~ms} 30 \mathrm{~min}$ after skin incision, whereas no patient did in the control group $(\mathrm{P}=0.01)$. No significant differences were observed between the two groups in mean blood pressure, body temperature, heart rate, or sevoflurane concentrations.

Conclusions: Palonosetron may induce QTc prolongation during the early general anesthesia period with sevoflurane. (Korean J Anesthesiol 2013; 65: 397-402)

Key Words: Cardiac arrhythmia, Electrocardiography, General anesthesia, Palonosetron, Patient safety, Sevoflurane.

Received: August 8, 2013. Revised: September 10, 2013. Accepted: September 11, 2013.

Corresponding author: Jung-Man Lee, M.D., Department of Anesthesiology and Pain Medicine, Seoul National University Hospital, Seoul National University College of Medicine, 101, Daehak-ro, Jongno-gu, Seoul 110-744, Korea. Tel: 82-2-2072-2469, Fax: 82-2-747-5639, E-mail: jungman007@gmail.com

(c) This is an open-access article distributed under the terms of the Creative Commons Attribution Non-Commercial License (http:// creativecommons.org/licenses/by-nc/3.0/), which permits unrestricted non-commercial use, distribution, and reproduction in any medium, provided the original work is properly cited. 


\section{Introduction}

Palonosetron is a 5-hydroxytryptamine-3 $\left(5-\mathrm{HT}_{3}\right)$ receptor antagonist with a powerful antiemetic effect useful for postoperative nausea and vomiting (PONV) prophylaxis. This agent has great potency and a longer duration of action than other $5-\mathrm{HT}_{3}$ receptor antagonists including ondansetron, granisetron, tropisetron, and dolasetron [1,2]. PONV is the most common side effect after general anesthesia, occurring in 30-70\% of patients according to PONV risk factors [3]. Perioperative use of a $5-\mathrm{HT}_{3}$ receptor antagonist is highly encouraged to prevent PONV in high-risk patients [4]. Several clinical studies have shown that palonosetron significantly reduces the incidence of PONV [5-8]. However, the safety of palonosetron during the perioperative period has not been established.

$5-\mathrm{HT}_{3}$ receptor antagonists including ondansetron increase the corrected QT (QTc) interval in patients who undergo general anesthesia [9]. Adverse cardiovascular events such as ventricular arrhythmia, myocardial ischemia, and cardiac arrest are also reported after administration of ondansetron [10,11]. Because of a similar pharmacologic mechanism, palonosetron may prolong the QTc interval and increase the risk for critical arrhythmias during general anesthesia. However, perioperative data on the cardiac safety of palonosetron are lacking. Although previous randomized studies reported that palonosetron did not increase the QTc interval in patients undergoing surgery, the primary outcomes of those studies were limited to PONV, and the anesthetic agents that potentially influenced QTc were not identified $[7,8]$. Because sevoflurane has been associated with QTc prolongation [12], the cardiac effect of palonosetron during sevoflurane anesthesia needs to be evaluated.

We hypothesized that palonosetron would increase the incidence of QTc prolongation in patients under general anesthesia with sevoflurane. This retrospective study was performed to evaluate whether palonosetron can be used safely during general anesthesia with sevoflurane.

\section{Materials and Methods}

This retrospective study was performed after approval by the Institutional Review Board of our hospital. The computerized hospital database was reviewed to identify subjects and collect data. We reviewed patients aged 20-90 years who underwent elective laparotomy under general anesthesia with sevoflurane between January and February 2012. We assessed whether palonosetron was administered intravenously during the perioperative period in each patient. Patients who received palonosetron immediately before induction of general anesthesia were enrolled in the palonosetron group. Patients who did not receive any kind of $5-\mathrm{HT}_{3}$ receptor antagonist intraoperatively were enrolled in the control group. Patients with ischemic heart disease, previous myocardial infarction, congestive heart failure, congenital long QT syndrome, preoperative QTc prolongation $>500 \mathrm{~ms}$, or significant arrhythmias including atrial fibrillation, bundle branch block, or atrioventricular block were excluded, because these are known risk factors for QTc prolongation and torsade de pointes [13]. Patients with an anesthetic duration $<2 \mathrm{~h}$ were also excluded.

Routine monitoring of blood pressure, three-lead electrocardiography, oxygen saturation, and body temperature were applied in all patients. Anesthesia was induced with 1.5-2.0 $\mathrm{mg} / \mathrm{kg}$ propofol, and tracheal intubation was performed after administration of $0.6-0.8 \mathrm{mg} / \mathrm{kg}$ rocuronium. Anesthesia was maintained using 1-4 vol\% sevoflurane in $\mathrm{O}_{2}$ and air.

Demographic and preoperative data were collected, including age, gender, body weight, height, medical history, preoperative potassium and calcium levels, and electrocardiogram (ECG). All preoperative medications such as antiarrhythmics, antibiotics, and antipsychotics were identified to determine whether they prolonged QTc [14-16]. The lead II ECG data recorded during the operation were retrieved from the server storage system, and ECG data before anesthetic induction, at skin incision, and 30, 60, 90, and $120 \mathrm{~min}$ after the incision were obtained. The QT and RR intervals on the ECG trace were measured manually by averaging five successive cardiac beats with a ruler by an anesthesiologist blinded to the patient groups as described previously [9]. The QT interval was defined as the onset of the QRS complex to the end of the $\mathrm{T}$ wave, which is the cross point between the descending slope of the T wave and the T-P isoelectric line. To preclude interference of heart rate on the QT interval, the QTc interval was calculated using Fridericia's formula: QTc = $\mathrm{QT} / \mathrm{RR}^{1 / 3}$ [17]. Patients with QTc intervals $>500 \mathrm{~ms}$ were identified at 30, 60, 90, and $120 \mathrm{~min}$ after skin incision [13]. Changes in the QTc interval from baseline were calculated. Mean arterial pressure, heart rate, body temperature, and expiratory sevoflurane concentrations were also collected at 30,60, 90, and 120 min after skin incision. Medications administered during general anesthesia such as ephedrine and fentanyl were recorded. The occurrence of arrhythmias during the perioperative period was evaluated.

The statistical analysis was performed using SPSS ver. 18.0 (SPSS Inc., Chicago, IL, USA). Student's $t$-test was used to compare continuous variables between the two groups. The chisquare test or Fisher's exact test was used to compare categorical variables. Changes in the QTc intervals measured on the ECG at several time points were analyzed using repeated-measures analysis of variance. Data are expressed as mean \pm standard deviation or number of patients $(\%)$. $\mathrm{P}$ values $<0.05$ were considered significant. 


\section{Results}

We reviewed the electronic medical records of 201 patients who underwent elective laparotomy under general anesthesia with sevoflurane between January and February 2012. Of the 201 patients, 120 were excluded because they did not meet the inclusion criteria. Ultimately, 81 patients were enrolled and ana-

Table 1. Demographic and Preoperative Data

\begin{tabular}{|c|c|c|c|}
\hline & $\begin{array}{l}\text { Palonosetron } \\
\quad(\mathrm{n}=40)\end{array}$ & $\begin{array}{l}\text { Control } \\
(\mathrm{n}=41)\end{array}$ & $P$ value \\
\hline Age (yr) & $53.1 \pm 15.4$ & $51.3 \pm 14.0$ & 0.58 \\
\hline Male & $20(50.0)$ & $21(51.2)$ & 1 \\
\hline Weight (kg) & $61.7 \pm 14.1$ & $58.8 \pm 8.9$ & 0.27 \\
\hline Height $(\mathrm{cm})$ & $161.4 \pm 9.9$ & $161.9 \pm 9.4$ & 0.8 \\
\hline \multicolumn{4}{|l|}{ Comorbidites } \\
\hline Hypertension & $11(27.5)$ & $9(22.0)$ & 0.61 \\
\hline Diabetes mellitus & $0(0)$ & $1(2.4)$ & 1 \\
\hline Hepatocelluar carcinoma & $1(2.5)$ & $6(14.6)$ & 0.11 \\
\hline Liver cirrhosis & $5(12.5)$ & $2(4.9)$ & 0.26 \\
\hline HBV infection & $5(12.5)$ & $9(22.0)$ & 0.38 \\
\hline Chronic kidney disease & $4(10.0)$ & $4(9.8)$ & 1 \\
\hline Schizophrenia & $0(0)$ & $1(2.4)$ & 1 \\
\hline \multicolumn{4}{|l|}{ Medications } \\
\hline Calcium channel blocker & $4(10.0)$ & $2(4.9)$ & 0.33 \\
\hline Angiotension receptor blocker & $4(10.0)$ & $4(10.0)$ & 0.63 \\
\hline QT prolonging drugs & 21 & 27 & \\
\hline Sertraline & $1(2.5)$ & $0(0)$ & 1 \\
\hline Clarithromycin & $1(2.5)$ & $0(0)$ & 1 \\
\hline Risperidone & $0(0)$ & $1(2.4)$ & 1 \\
\hline Ciprofloxacin & $1(2.5)$ & $1(2.4)$ & 1 \\
\hline Levofloxacin & $2(5.0)$ & $0(0)$ & 0.24 \\
\hline Moxifloxacin & $10(25.0)$ & $18(43.9)$ & 0.1 \\
\hline Famotidine & $5(12.5)$ & $18(43.9)$ & $0.003 *$ \\
\hline Tacrolimus & $3(7.5)$ & $4(9.8)$ & 1 \\
\hline \multicolumn{4}{|l|}{ Preoperative electrolyte level } \\
\hline Potassium (mmol/L) & $4.3 \pm 0.3$ & $4.2 \pm 0.3$ & 0.19 \\
\hline Calcium (mg/dl) & $9.2 \pm 0.5$ & $9.0 \pm 0.7$ & 0.25 \\
\hline \multicolumn{4}{|l|}{ Preoperative ECG } \\
\hline Sinus bradycardia & $10(25.0)$ & $8(19.5)$ & 0.6 \\
\hline QTc interval & $433.2 \pm 25.5$ & $429.1 \pm 20.9$ & 0.44 \\
\hline Prolonged QTc interval $^{\dagger}$ & $3(7.5)^{\ddagger}$ & $0(0)$ & 0.12 \\
\hline
\end{tabular}

Data are expressed as mean \pm SD or number of patients (\%). ECG: electrocardiogram, QTc: corrected QT. ${ }^{*} \mathrm{P}<0.05$ between two groups. ${ }^{\dagger}$ Prolonged QTc interval in males is a QTc above $450 \mathrm{~ms}$, and in females, above $470 \mathrm{~ms} .{ }^{\ddagger}$ Three patients in the palonosetron group who had prolonged preoperative QTc interval were all male. lyzed. Of the enrolled patients, 40 who received $0.075 \mathrm{mg}$ intravenous palonosetron (Aloxi ${ }^{\circledR}$, Helsinn Healthcare, SA, Lugano, Switzerland) immediately before induction of general anesthesia according to the anesthesiologist's preference were assigned to the palonosetron group, and 41 patients who did not receive any kind of $5-\mathrm{HT}_{3}$ receptor antagonist including palonosetron until completion of surgery were assigned to the control group.

Demographic and preoperative characteristics of the patients are shown in Table 1. Age, gender, coexisting diseases, and medications except famotidine were similar between the two groups (Table 1). Sertraline, clarithromycin, risperidone, ciprofloxacin, levofloxacin, moxifloxacin, famotidine, and tacrolimus, which are QT-prolonging drugs [16], were identified. The number of patients who received at least one of these drugs was not different between the two groups. Preoperative calcium and potassium levels, sinus bradycardia, QTc interval, and the number of patients with a prolonged QTc interval on the preoperative ECG were not different between the two groups (Table 1). The preoperative QTc interval was considered prolonged when it was $>$ $450 \mathrm{~ms}$ in male patients and $>470 \mathrm{~ms}$ in female patients. None of the patients were hypokalemic before surgery.

The QTc intervals on the ECG before and during general anesthesia are presented in Table 2. No significant difference in baseline QTc interval was observed between the two groups. The QTc intervals at skin incision and 30, 60, 90, 120 min after skin incision during general anesthesia increased significantly compared to those at baseline in both groups $(\mathrm{P}<0.001)$. The changes in the QTc intervals were not different between the two groups $(\mathrm{P}=0.41)$. The mean individual maximum QTc interval from baseline to $120 \mathrm{~min}$ after skin incision was $468.2 \pm 33.2 \mathrm{~ms}$ in the control group and $471.2 \pm 38.0 \mathrm{~ms}$ in the palonosetron group $(\mathrm{P}=0.70)$. Fig. 1 shows the number of patients in whom QTc intervals were $>500 \mathrm{~ms}$ at each time point during general anesthesia. Six patients in the palonosetron group had a QTc interval > $500 \mathrm{~ms} 30 \mathrm{~min}$ after skin incision, whereas no patient did in the control group (Fig. 1, Table 3). No significant differences were observed between the groups for the number of patients who experienced a QTc interval > $500 \mathrm{~ms}$ at other time points except $30 \mathrm{~min}$ after skin incision. The proportion of patients who experienced an increase in QTc interval of $>30$ or 60 ms was not significantly different between the two groups.

Table 2. QTc Interval (ms) on ECG before and during General Anesthesia

\begin{tabular}{|c|c|c|c|c|c|c|}
\hline & \multirow{2}{*}{ Baseline } & \multirow{2}{*}{ Skin incision } & \multicolumn{4}{|c|}{ Minutes after skin incision } \\
\hline & & & 30 & 60 & 90 & 120 \\
\hline Palonosetron $(\mathrm{n}=40)$ & $412.1 \pm 25.9$ & $434.3 \pm 34.9 *$ & $454.6 \pm 39.0 *$ & $453.9 \pm 35.0 *$ & $453.1 \pm 36.7^{*}$ & $454.6 \pm 38.6^{*}$ \\
\hline Control $(\mathrm{n}=41)$ & $408.3 \pm 25.2$ & $431.8 \pm 34.7^{*}$ & $440.1 \pm 38.8^{*}$ & $449.7 \pm 34.0^{*}$ & $450.3 \pm 34.1^{*}$ & $449.8 \pm 35.1^{*}$ \\
\hline
\end{tabular}

Baseline QTcintervals were obtained before induction of anesthesia. Data are expressed as mean \pm SD. ECG: electrocardiogram, QTc interval: corrected QT interval. * $\mathrm{P}<0.001$ within the group, compared with baseline. 


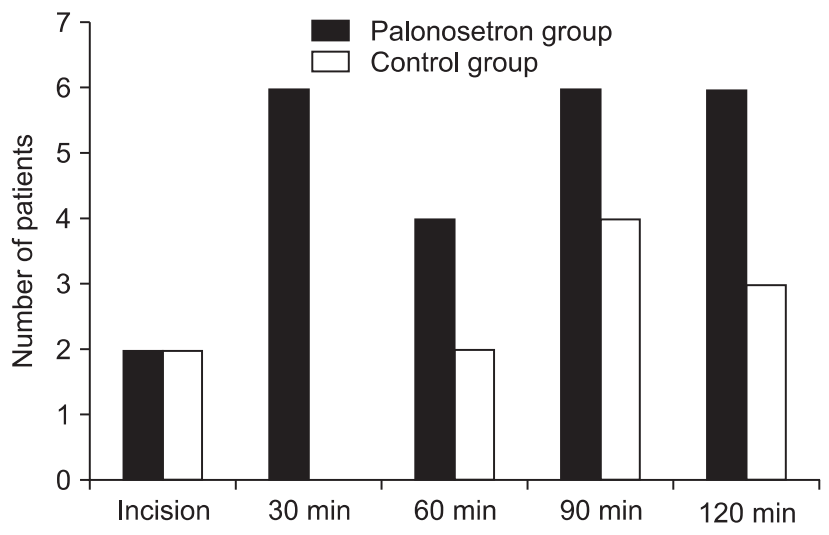

Fig. 1. The number of patients in whom QTc interval $>500 \mathrm{~ms}$ during general anesthesia.

The QTc intervals, hemodynamic values, and medications at 30 min after skin incision are shown in Table 3. No significant differences were observed between the groups for mean blood pressure, body temperature, heart rate, sevoflurane concentrations, and number of patients in whom ephedrine or fentanyl was administered intravenously during anesthesia. A significant arrhythmia occurred in one patient in the palonosetron group. That patient developed ventricular tachycardia at $55 \mathrm{~min}$ after skin incision, but his ECG normalized after defibrillation. $\mathrm{He}$ presented a higher QTc interval of $521.5 \mathrm{~ms}$ at $30 \mathrm{~min}$ after skin incision compared to the baseline value of $462.5 \mathrm{~ms}$.

\section{Discussion}

The main finding of our study was that the incidence of QTC prolongation $>500 \mathrm{~ms}$ increased when patients received intravenous palonosetron before induction of general anesthesia. This QTc prolongation was observed during the initial period of general anesthesia with sevoflurane.

Palonosetron is the safest antiemetic among 5- $\mathrm{HT}_{3}$ receptor antagonists with regard to cardiovascular side effects [1]. The QT interval does not increase significantly after administration of palonosetron in patients with cancer undergoing chemotherapy $[18,19]$. In some previous prospective randomized dose-ranging studies that targeted patients undergoing surgery, the increase in QT interval was similar regardless of palonosetron administration $[7,8]$. However, patients with preoperative QTc intervals > $500 \mathrm{~ms}$ may have been included in those studies because the preoperative ECG was not confirmed and QTprolonging risk factors such as hypokalemia, hypothermia, and medications were not identified. In addition, the acute cardiac effects of palonosetron during general anesthesia may have been undetected because the QTc interval measurements were only assessed at $15 \mathrm{~min}$ and 3-6 h after palonosetron injection. Moreover, no information was provided about the surgery time inter-
Table 3. QTc Interval, Hemodynamic Variables and Concomitant Drugs at 30 Minutes after Skin Incision

\begin{tabular}{|c|c|c|c|}
\hline & $\begin{array}{l}\text { Palonosetron } \\
\quad(\mathrm{n}=40)\end{array}$ & $\begin{array}{l}\text { Control } \\
(\mathrm{n}=41)\end{array}$ & $P$ value \\
\hline \multicolumn{4}{|l|}{ Electrocardiographics } \\
\hline QTc interval (ms) & $454.6 \pm 39.0$ & $440.1 \pm 38.8$ & 0.12 \\
\hline QTc interval > $500 \mathrm{msec}$ & $6(15.0)$ & $0(0)$ & $0.01 *$ \\
\hline Prolonged QTc interval $^{\dagger}$ & $15(37.5)$ & $16(39.0)$ & 0.89 \\
\hline$\Delta \mathrm{QTc}$ interval $>60 \mathrm{msec}$ & $13(32.5)$ & $11(26.8)$ & 0.63 \\
\hline$\Delta \mathrm{QTc}$ interval $>30 \mathrm{msec}$ & $24(60.0)$ & $19(46.3)$ & 0.27 \\
\hline \multicolumn{4}{|l|}{ Hemodynamics } \\
\hline Mean blood pressure, $\mathrm{mmHg}$ & $82.4 \pm 20.1$ & $78.1 \pm 15.6$ & 0.29 \\
\hline Body temperature $\left({ }^{\circ} \mathrm{C}\right)$ & $35.6 \pm 0.5$ & $35.7 \pm 0.4$ & 0.27 \\
\hline Heart rate (beats/min) & $73.9 \pm 11.4$ & $76.1 \pm 13.7$ & 0.44 \\
\hline \multicolumn{4}{|l|}{ Concomitant drugs } \\
\hline $\begin{array}{l}\text { Concentration of sevoflurane } \\
\text { (vol\%) }\end{array}$ & $2.2 \pm 0.6$ & $2.1 \pm 0.4$ & 0.44 \\
\hline Ephedrine & $14(35.0)$ & $11(26.8)$ & 0.47 \\
\hline Fentanyl & $4(10.0)$ & $4(9.8)$ & 1.00 \\
\hline Labetalol & $1(2.5)$ & $2(4.9)$ & 1.00 \\
\hline Phenylephrine & $1(2.5)$ & $0(0)$ & 0.49 \\
\hline Calcium chloride & $1(2.5)$ & $0(0)$ & 0.49 \\
\hline Nicardipine & $1(2.5)$ & $1(2.5)$ & 1.00 \\
\hline
\end{tabular}

Data are expressed as mean \pm SD or number of patients (\%). QTc interval; corrected QT interval. $\triangle$ QTc interval; the increase in QTc interval from baseline. ${ }^{*} \mathrm{P}<0.05$ between the two groups. ${ }^{\dagger}$ Prolonged QTc interval in males is a QTc above $450 \mathrm{~ms}$, and in females, above 470 ms.

val or QTc measurements. Therefore, the necessity to investigate the relationship between QTc prolongation and palonosetron remains and a clinical study of which the primary outcome is cardiac side effects of palonosetron during general anesthesia is warranted.

Ondansetron, which is another $5-\mathrm{HT}_{3}$ antagonist, has been associated with QTc prolongation, myocardial ischemia, and fatal arrhythmias in patients undergoing cancer chemotherapy [10] or surgery $[9,20]$. The exact pharmacologic mechanism has not been established; however, the blocking of cardiac sodium or potassium channels, delays in cardiac repolarization, or coronary vasoconstriction via cardiac 5-HT-receptor have been postulated to precipitate QTc prolongation and significant arrhythmias [21]. Therefore, palonosetron could theoretically have a QTc prolonging effect with a similar mechanism as ondansetron.

In contrast to previous studies $[7,8]$, we found that a QTc interval $>500$ ms occurred more frequently after administering palonosetron compared to the control group, suggesting that the combination of palonosetron, sevoflurane, and sympathetic stimulation such as a skin incision may have initiated the significant QT prolongation and ventricular arrhythmia. Similarly, a previous study demonstrated that the additive QT-prolonging effect of isoflurane and anthracycline was due to an increase in the incidence of QTc prolongation in patients undergoing breast 
surgery [22]. Sevoflurane increases the QT interval in a dosedependent manner [12,23]. In addition, sympathetic activation, caused by tracheal intubation, surgical incision, or emergence, increases the QT interval [14,24], and this QT-prolonging effect of sympathetic stimulation is prevented by administering an opioid $[25,26]$. Moreover, we used time points based on the skin incision, which was $35.1 \pm 9.9 \mathrm{~min}$ after the palonosetron injection, so a surgical stimulatory effect on the QTc interval in addition to the palonosetron effect could have been observed. In the present study, palonosetron may have increased the incidence of QTc prolongation through a combined effect of sevoflurane and surgical stimulation. This is the reason why an increase in QTc interval was not reported in patients with cancer who did not have general anesthesia $[18,19]$. Our results show that other possible QT prolongation risk factors [18,27-29], including older age, female gender, known QT-prolonging drugs, preoperative QT interval, preoperative bradycardia, preoperative hypokalemia, heart failure, myocardial ischemia, sevoflurane concentrations, temperature, ephedrine, and fentanyl were not different between the two groups.

We observed the ECG during the initial $2 \mathrm{~h}$ after injecting palonosetron according to the guidelines [15], which suggest monitoring the QT interval during the peak plasma concentration of the QT-prolonging medication. In a previous report, the time to reach the maximum plasma concentration after intravenous administration of palonosetron was 2-9 min when a dose of $1-3 \mu \mathrm{g} / \mathrm{kg}$ was used in surgical patients [1]. Therefore, a clinical study that investigates the effect of palonosetron during a short period with small intervals after injecting palonosetron is needed. Furthermore, we used Fridericia's formula to calculate the QTc interval, which has less dependency on heart rate compared to that of Bazett's formula [17,26]. Fridericia's formula diagnoses a prolonged QTc interval more correctly because heart rate is very changeable during anesthesia.

This study has several limitations. First, it was not a randomized prospective study. Thus, several factors that may have affected the QTc interval (e.g., a circadian effect, drugs used, and the depth of anesthesia at the time points) were not controlled. However, several risk factors that can affect QT prolongation [14] were similar between the two groups, except famotidine, and we used Fridericia's formula to minimize the effect of circadian heart rate variability in the QTc analysis. Anesthetic management was standardized to maintain a bispectral index of 4060 in all patients during the study period. Further prospective randomized studies focusing on the cardiovascular effects of palonosetron during general anesthesia are needed. Second, an arrhythmia was detected in only one patient in the palonosetron group, although the incidence of QTc prolongation > $500 \mathrm{~ms}$ increased significantly in the palonosetron group 30 min after skin incision. There is controversy about the value of QTc interval, which is considered a surrogate marker for the risk of arrhythmias [30]. However, the QTc interval still remains the standard for monitoring cardiac safety of $5-\mathrm{HT}_{3}$ receptor antagonists [13].

In conclusion, the incidence of QTc prolongation > $500 \mathrm{~ms}$ was higher in patients who received $0.075 \mathrm{mg}$ intravenously administered palonosetron, compared to those who did not during general anesthesia with sevoflurane. Palonosetron may induce QTc prolongation during earlier periods of general anesthesia with sevoflurane.

\section{References}

1. Yang LP, Scott LJ. Palonosetron: in the prevention of nausea and vomiting. Drugs 2009; 69: 2257-78.

2. Saito M, Tsukuda M. Review of palonosetron: emerging data distinguishing it as a novel 5-HT(3) receptor antagonist for chemotherapyinduced nausea and vomiting. Expert Opin Pharmacother 2010; 11: 1003-14.

3. Gan TJ. Risk factors for postoperative nausea and vomiting. Anesth Analg 2006; 102: 1884-98.

4. Gan TJ, Meyer T, Apfel CC, Chung F, Davis PJ, Eubanks S, et al. Consensus guidelines for managing postoperative nausea and vomiting. Anesth Analg 2003; 97: 62-71.

5. Park SK, Cho EJ. A randomized, double-blind trial of palonosetron compared with ondansetron in preventing postoperative nausea and vomiting after gynaecological laparoscopic surgery. J Int Med Res 2011; 39: 399-407.

6. Moon YE, Joo J, Kim JE, Lee Y. Anti-emetic effect of ondansetron and palonosetron in thyroidectomy: a prospective, randomized, doubleblind study. Br J Anaesth 2012; 108: 417-22.

7. Candiotti KA, Kovac AL, Melson TI, Clerici G, Joo Gan T. A randomized, double-blind study to evaluate the efficacy and safety of three different doses of palonosetron versus placebo for preventing postoperative nausea and vomiting. Anesth Analg 2008; 107: 445-51.

8. Kovac AL, Eberhart L, Kotarski J, Clerici G, Apfel C. A randomized, double-blind study to evaluate the efficacy and safety of three different doses of palonosetron versus placebo in preventing postoperative nausea and vomiting over a 72-hour period. Anesth Analg 2008; 107: 43944.

9. Charbit B, Albaladejo P, Funck-Brentano C, Legrand M, Samain E, Marty J. Prolongation of QTc interval after postoperative nausea and vomiting treatment by droperidol or ondansetron. Anesthesiology 2005; 102: 1094-100.

10. Ballard HS, Bottino G, Bottino J. Ondansetron and chest pain. Lancet 1992; 340: 1107. 
11. Bosek V, Hu P, Robinson LA. Acute myocardial ischemia after administration of ondansetron hydrochloride. Anesthesiology 2000; $92: 885-7$.

12. Kuenszberg E, Loeckinger A, Kleinsasser A, Lindner KH, Puehringer F, Hoermann C. Sevoflurane progressively prolongs the QT interval in unpremedicated female adults. Eur J Anaesthesiol 2000; 17: 662-4.

13. Drew BJ, Ackerman MJ, Funk M, Gibler WB, Kligfield P, Menon V, et al. Prevention of torsade de pointes in hospital settings: a scientific statement from the American Heart Association and the American College of Cardiology Foundation. Circulation 2010; 121: 1047-60.

14. Booker PD, Whyte SD, Ladusans EJ. Long QT syndrome and anaesthesia. Br J Anaesth 2003; 90: 349-66.

15. Al-Khatib SM, LaPointe NM, Kramer JM, Califf RM. What clinicians should know about the QT interval. JAMA 2003; 289: 2120-7.

16. Khan IA. Clinical and therapeutic aspects of congenital and acquired long QT syndrome. Am J Med 2002; 112: 58-66.

17. Fridericia LS. The duration of systole in an electrocardiogram in normal humans and in patients with heart disease. 1920. Ann Noninvasive Electrocardiol 2003; 8: 343-51.

18. Yavas C, Dogan U, Yavas G, Araz M, Ata OY. Acute effect of palonosetron on electrocardiographic parameters in cancer patients: a prospective study. Support Care Cancer 2012; 20: 2343-7.

19. Gonullu G, Demircan S, Demirag MK, Erdem D, Yucel I. Electrocardiographic findings of palonosetron in cancer patients. Support Care Cancer 2012; 20: 1435-9.

20. Baguley WA, Hay WT, Mackie KP, Cheney FW, Cullen BF. Cardiac dysrhythmias associated with the intravenous administration of ondansetron and metoclopramide. Anesth Analg 1997; 84: 1380-1.

21. Kuryshev YA, Brown AM, Wang L, Benedict CR, Rampe D. Interactions of the 5-hydroxytryptamine 3 antagonist class of antiemetic drugs with human cardiac ion channels. J Pharmacol Exp Ther 2000; 295: 614-20.

22. Owczuk R, Wujtewicz MA, Sawicka W, Wujtewicz M, Swierblewski M. Is prolongation of the QTc interval during isoflurane anaesthesia more prominent in women pretreated with anthracyclines for breast cancer? Br J Anaesth 2004; 92: 658-61.

23. Sen S, Ozmert G, Boran N, Turan H, Caliskan E. Comparison of single-breath vital capacity rapid inhalation with sevoflurane $5 \%$ and propofol induction on QT interval and haemodynamics for laparoscopic surgery. Eur J Anaesthesiol 2004; 21: 543-6.

24. Nathan AT, Berkowitz DH, Montenegro LM, Nicolson SC, Vetter VL, Jobes DR. Implications of anesthesia in children with long QT syndrome. Anesth Analg 2011; 112: 1163-8.

25. Cafiero T, Di Minno RM, Di Iorio C. QT interval and QT dispersion during the induction of anesthesia and tracheal intubation: a comparison of remifentanil and fentanyl. Minerva Anestesiol 2011; 77: 160-5.

26. Kweon TD, Nam SB, Chang CH, Kim MS, Lee JS, Shin CS, et al. The effect of bolus administration of remifentanil on QTc interval during induction of sevoflurane anaesthesia. Anaesthesia 2008; 63: 347-51.

27. Cubeddu LX. Iatrogenic QT Abnormalities and Fatal Arrhythmias: Mechanisms and Clinical Significance. Curr Cardiol Rev 2009; 5: 16676.

28. Yap YG, Camm AJ. Drug induced QT prolongation and torsades de pointes. Heart 2003; 89: 1363-72.

29. Roden DM. Drug-induced prolongation of the QT interval. N Engl J Med 2004; 350: 1013-22.

30. Antzelevitch C. Arrhythmogenic mechanisms of QT prolonging drugs: is QT prolongation really the problem? J Electrocardiol 2004; 37 Suppl: 15-24. 